\title{
Open-field behavior of wild and domestic Norway rats
}

\author{
EDWARD O. PRICE and U. WILLIAM HUCK \\ Department of Zoology, State University of New York College of Environmental Science and Forestry
} Syracuse, New York 13210

\begin{abstract}
The open-field behavior of wild and domestic Norway rats was compared in 15-min tests administered over 5 successive days. Wild rats exhibited more ambulation, jumping, grooming, and time inactive than domestic rats and spent more time along the arena wall. Within-and between-trial changes in behavior were generally greater for wild rats. Factor analyses revealed major loadings on factors identified as "locomotor behavior" and "grooming." Support was obtained for the hypothesis that domestication has raised the threshold for avoidance-escape behavior in response to a novel environment.
\end{abstract}

One of the major effects of domestication on the behavior of the Norway rat is a reduction in emotional reactivity (see review by Boice, 1973). In nature, the response of the rat to changes in its environment is of considerable importance to its survival (Chitty, 1954; Davis, 1953; Shorten, 1954). In the confines of relatively small laboratory enclosures, the response to novelty (except, perhaps, in the context of social or sexual behavior) is of questionable importance to individual adaptation and fitness (Price \& King, 1968). In addition, artificial selection for docility and reduced emotionality has undoubtedly been applied to render the Norway rat more amenable to laboratory study.

Barnett (1958a), Shorten (1954), and Sloan (1973) report that wild rats are more cautious in approaching unfamiliar stimuli placed in an otherwise familiar environment. However, studies comparing the responses of wild and domestic rats to a totally unfamiliar environment (i.e., open-field) have produced somewhat conflicting results. Farris and Yeakel (1945) compared the open-field behavior of Wistar albino rats and wild rats representing the 43 rd generation of a captive population. Neither stock nor sex differences in defecation rate were statistically significant. Ambulation and jumping, although not quantified, were reported to be greater for wild rats regardless of defecation scores. Broadhurst (1958) reported that the mean ambulation score of 17 male wild subjects (of unknown age and history) was intermediate to the five domestic stocks employed. Mean defecation rate was highest for wild rats but not statistically different from at least two of the five domestic stocks. In a more recent study, designed to assess the effects of the maternal environment, Price and Loomis (1973) found that wild rats were more active and groomed more than domestic rats in an unfamiliar enclosure while defecation rates did not differ. Hughes (1975) reported that preweaning handling had a significant influence on the open-field behavior of wild Norway rats but that the effects of cross-fostering and postweaning in enriched environments were negligible. In contrast, Huck and Price (1975) found that early

This investigation was supported by Grant MH21467-01 from the National Institute of Mental Health to E. Price. postweaning experience in an enriched environment significantly influenced the open-field behavior and body weight of both wild and domestic rats. In addition, Hughes reported that wild rats were consistently less active than domestic subjects in the open-field, while Huck and Price found just the opposite. However, both studies agree that wild rats groom and defecate more than their domestic counterparts and that wild rats exhibit more marked changes in behavior over successive test periods.

The conflicting data obtained in the aforementioned studies have precluded a clear synthesis of the behavioral differences of wild and domestic Norway rats when placed in a totally unfamiliar environment. The purpose of the following study was to further clarify the effect of domestication on the open-field behavior of this species. Some 17 behavior patterns were measured and subjected to factor analysis.

\section{METHOD}

\section{Subjects}

Twenty wild and 20 domestic (Long-Evans) rats, divided equally by sex, were used in the present study. Domestic males averaged 215 days of age (range: 175-250) and $480 \mathrm{~g}$ body weight (range: 388-571) at the start of testing, while domestic females averaged 234 days (range: 222-249) and $327 \mathrm{~g}$ (range: 263-398). The domestic stock represented 11 different litters.

Wild subjects were conceived in the laboratory and represented the offspring of 15 pairs of field-trapped rats. Wild males averaged 206 days (range: 200-211) and $326 \mathrm{~g}$ (range: 293-361) at the start of testing, while wild females averaged 213 days (range: 183-261).

All subjects were weaned at $25 \pm 1$ days of age and maintained in $14 \times 14 \times 7$ in. metal wire bottom cages in groups of 2 or 3 rats (like sex) until testing. Handling prior to testing was minimal. Subjects were maintained on a 12:12 light-dark cycle with light commencing at $0700 \mathrm{~h}$. Testing was conducted during the light phase. Rats were given Charles River Rat and Mouse Diet and water ad lib.

\section{Apparatus}

A circular open-field was constructed of an 8-ft-diam plywood base and a 44-in.-high sheet metal wall. The interior was painted white, and the floor was divided by five concentric circles and a number of radial lines into 66 sectors, each with an area of approximately $108 \mathrm{sq}$ in. The apparatus was illuminated by fluorescent lamps (approximately $35 \mathrm{fc}$ ) and was located in a $21 \times 11 \times 8 \mathrm{ft}$ experimental room maintained at $72 \pm 1^{\circ} \mathrm{F}$ and 
Table 1

Open-Field Behavior of Wild and Domestic Norway Rats: Mean Scores (Test Days Combined)

\begin{tabular}{lrrrr}
\hline & \multicolumn{2}{c}{ Wild } & \multicolumn{2}{c}{ Domestic } \\
& Male & Female & Male & leinale \\
\hline Time on side (min) & 14.5 & 14.3 & 14.0 & 10.5 \\
Ambulation on side & 86.5 & 85.4 & 53.6 & 70.8 \\
Percent ambulation on side & 72.0 & 63.5 & 79.3 & 62.3 \\
Ambulation in center & 35.1 & 55.2 & 16.0 & 33.7 \\
Total ambulation & 121.6 & 140.6 & 69.6 & 104.5 \\
Side-center crossings & 5.4 & 7.0 & 2.8 & 4.9 \\
Inactivity bouts & 1.7 & 1.9 & 1.4 & 1.1 \\
Time inactive (sec) & 327.9 & 461.1 & 107.4 & 129.2 \\
Rearing (freq) & 24.4 & 20.9 & 7.9 & 9.9 \\
Jumping (freq) & 1.3 & .4 & .0 & .0 \\
Facial grooming bouts & 12.8 & 8.0 & 8.0 & 7.7 \\
Time facial grooming (sec) & 75.8 & 53.0 & 60.5 & 72.5 \\
Percent time facial grooming & 36.6 & 46.2 & 84.4 & 75.7 \\
Body groorning bouts & 12.8 & 7.4 & 4.3 & 5.2 \\
Time body grooming (sec) & 120.6 & 76.2 & 16.4 & 27.0 \\
Total grooming time (sec) & 214.2 & 130.6 & 76.9 & 100.2 \\
Defecation & 2.1 & 1.4 & .9 & 1.9 \\
\hline C. & &
\end{tabular}

*Includes any time spent tail grooming.

$50 \pm 7 \%$ relative humidity. White noise (approximately $75 \mathrm{~dB}$ ) was continually played during testing. All data recording apparatus (e.g., event recorder, counters, timers, etc.) were located outside the experimental room and observations were made through a one-way mirror.

\section{Procedure}

Subjects were isolated in individual cages on the day preceding Trial 1. Transfers from home cages to the test apparatus were made in a $6 \times 4 \times 6 \mathrm{n}$. wooden handling box with a removable sliding door. The handling box was placed in the center of the open field with the sliding door facing the floor. The door (bottom) was removed and after a 2 -min acclimation period the box was raised from the subject by means of a rope and pulley system, and the tral started.

Fach subject was tested in the open field for $15 \mathrm{~mm}$ on each of 5 consecutive days. The following data were recorded (1) ambulation-side inumber of sectors entered along wall of arena), (2) ambulation-center (number of remaining or inner sectors entered), (3) time-side (time spent in outermost sectors along wall), (4) side-center crossings (frequency of movement from inner to outermost sectors or vice versa), (5) inactivity (frequency and duration of periods of immobility, (6) defecation (number of fecal boluses deposited), (7) rearing (frequency of standing on hind limbs), (8) jumping (frequency of all four limbs leaving floor), (9) facial grooming (frequency and duration), and (10) body grooming (frequency and duration). From these data, four additional variables were computed. (11) total ambulation (sectors entered), (12) percent ambulation on side, (13) total time grooming, and (14) percent of total grooming time spent in facial grooming.

The data for all variables were computer analyzed by appropriate analysis of variance procedures. In addition, within-trial changes in behavior ( 6 variables) were analyzed by subdividing each trial into five 3 -min periods and recording the number of 2 -sec intervals during each $3-\mathrm{m} 1 \mathrm{n}$ pernod in which a given behavinr was observed. Student-Neuman-Keuls tests at the 0.05 alpha level (Sokol \& Rohlf, 1969) were used to conduct a posteriori multiple comparisons for both between- and withntrials data.

Factor analyses of the data (stocks and sexes separate) were conducted using Program BMDO3M in the Biomedical Series. This program performs a principal component solution and an orthogonal rotation of the factor matru (orrelation matrues were included in the output.

\section{RESULTS}

Mean open-field cores are presented in Table 1.

\section{Ambulation}

Wild rats exhibited significantly higher total ambulation scores than domestic subjects $(\mathrm{F}=11.8, \mathrm{df}=1 / 180$, $\mathrm{p}<.001$ ). However, stocks (sexes combined) did not differ in percent ambulation along the side (wall) of the arena.

Females ambulated more than males $(\mathrm{F}=4.4 \mathrm{df}=$ $1 / 180, p<.05)$ but only when in the center of the arena $(\mathrm{F}=11.0, \mathrm{df}=1 / 180, \mathrm{p}<.001)$. Consequently, males exhibited a higher percentage of ambulation scores along the wall than females $(F=28.8, \mathrm{df}=1 / 180, \mathrm{p}<.001)$, a difference that was more pronounced for domestic rats than their wild counterparts $(F=10.8$, df $=1 / 180$, $\mathrm{p}<.001$ ).

The main effect for trials was significant for total ambulation $\left(\mathrm{F}=7.8, \mathrm{df}^{\prime}=4 / 180, \mathrm{p}<.001\right)$ and ambulation on the side $(F=16.2$, df $=4 / 180, p<.001)$ only. Ambulation during Trial 1 was significanily greater than ambülation durng subsequent trals (which did not differ). Ambulation along the wall of the arena decreased more rapidly over trials for wild rats than their domestic counterparts $(F=2.6$, df $=4 / 180, p<.05)$. Ambulation in the center of the arana did not differ over days.

The number of crossings from side to center sectors and vice versa was greater for wild rats than domestic subjects $(\mathrm{F}=11.0, \mathrm{df}=1 / 180, \mathrm{p}<.001)$ and greater for females thar males $(\mathrm{F}=7.0, \mathrm{df}=1 / 180, \mathrm{p}<.01)$. The number of crossings per trial decreased for males between Trials 1 and 5 , whereas females exhibited no change over days $(F=2.5, \mathrm{df}=4 / 180 . \mathrm{p}<.05)$.

\section{Wall-Seeking}

All subjects spent most of each trial in the sectors nearest the wall of the arena (see Table 1). Even so, wild rats spent more time on the side than domestic subjects $(\mathrm{F}=26.0, \mathrm{df}=1 / 180, \mathrm{p}<.001)$ and males kept to the wall more consistently than females ( $F=$ $20.3, \mathrm{df}=1 / 180, \mathrm{p}<.001)$. Domestic males and females differed more in this regard than wild males and females $(\mathrm{F}=16.5$, df $=1 / 180, \mathrm{p}<.001)$. Time on the side did not change significantly over trials.

\section{Inactivity}

Wild rats exhibited more frequent bouts of inactivity than domestic rats $(F=7.7, \mathrm{df}=1 / 180, \mathrm{p}<.01)$ and were inactive for longer periods of time $(F=87.8$, $\mathrm{df}=1 / 180, p<.001)$. Female subjects were more nactive than males $(\mathrm{F}=6.9$, $\mathrm{df}=1 / 180, \mathrm{p}<.01)$. Inactivity scores were lowest for wild rats during Tral 1 when ambulation scores were highest. No differences 
were obtaned over trials for domestic subjects and for Truals 2.5 for wild rats.

\section{Defecation}

Although wild rats tended to defecate more than domestic rats, this difference was marginally significant $(\mathrm{F}=3.5, \mathrm{df}=1 / 180, \mathrm{p}<.10)$. A significant Stock by Sex interaction $(F=17.6, \mathrm{df}=1 / 180, \mathrm{p}<.001)$ was at tributable to higher defecation rates by wild males and domestic females, respectively.

\section{Rearing}

Wild rats reared more frequently than domestic rats $(\mathrm{F}=44.6$, df $=1 / 180, \mathrm{p}<.001)$ during all trials. Rearing by wild rats was more than four times greater during Trial 1 than for the remaining four trials. A trial effect was not obtained for domestic subjects.

\section{Jumping}

Fifteen of 20 wild rats jumped at least once during the course of testing. None of the domestic rats jumped. Wild males jumped more frequently than wild females $(\mathrm{F}=4.8, \mathrm{df}=1 / 90, \mathrm{p}<.05)$. Jumping frequency was significantly greater on Trial 1 than on subsequent days (which did not differ statistically).

\section{Grooming}

Wild rats spent more total time grooming than domestic rats $(F=39.1$, df $=1 / 180, p<.001)$. While the two stocks displayed nearly equal amounts of time facial grooming (Table 1), they differed markedly in time spent body grooming $(\mathrm{F}=71.9, \mathrm{df}=1 / 180, \mathrm{p}<.001)$. As a result, wild rats spent proportionately less time facial grooming $(F=266.3, \mathrm{df}=1 / 180, \mathrm{p}<.001)$.

Wild males groomed more than wild females, whereas the reverse was true of domestic rats. This interaction was significant $(\mathrm{p}<.01$ or lower) for all grooming variables except "percent facial grooming."

Percent time spent facial grooming tended to decrease over trials for female rats but remained constant for male subjects. This interaction was marginally significant $(F=2.5, \mathrm{df}=4 / 180, \mathrm{p}<.05)$.

\section{Within-Trial Changes in Behavior}

The behavior of wild rats changed more within trials than that of their domestic counterparts for 5 of 6 variables analyzed. While ambulation in both side and center sectors decreased $80 \%$ and $79 \%$, respectively, for wild rats as trials progressed, domestic rats exhibited $34 \%$ and $43 \%$ decreases in ambulation between highest and lowest scoring 3-min periods.

Both stocks spent significantly less time along the wall of the arena during the first $3 \mathrm{~min}$ of testing. Thereafter, scores did not change for either stock.

Both stocks became more inactive as trials progressed. All but the last 3-min period represented statistically significant increases for wild rats, whereas only the first and second periods differed for domestic rats.

Facia! grooming decreased for both stocks as trials progressed. However, the change was more marked for wild rats. Body grooming was most frequent midway through the trials. While body grooming changed significantly for wild rats during trials, the differences were not significant for domestic rats.

\section{Between-Trials Changes in Behavior}

Significant main effects for trials were obtained for (1) ambulation along the wall, (2) percent ambulation along the wall, (3) total ambulation, (4) rearing, (5) jumping, (6) time inactive, and (7) percent time faciai grooming. Aithough only three of these seven variables $(1,4$, and 6$)$ also yielded significant Stock by Trial interactions, in all cases wild rats exhibited greater changes in behavior over trials than their domestic counterparts. Except for time inactive by wild rats, all scores decreased between Trials 1 and 5 .

\section{Correlation Analyses}

Several general observations were made from the correlation matrices. First, a high degree of correlation was generally found between the various ambulation measures, side to center crossings, and rearing. Time on the side correlated fairly well with the above activity measures for wild rats but not for their domestic counterparts. With the exception of percent time facial grooming, all of the grooming variables were highly correlated. Jumping by wild rats was positively correlated with total ambulation and negatively related to time along the arena wall and time inactive. Defecation did not correlate with any of the other variables.

\section{Factor Analyses}

Major loadings from the factor analyses are presented in Table 2. With the exception of domestic males, a factor labeled "locomotion" could account for nearly half of the total variance. Included in this factor were nearly all the ambulation variables, inactivity (negative loadings), and rearing. Of particular interest is the fact that "time on the side" showed a major loading on this factor for wild rats but not for their domestic counterparts. Percent ambulation along the arena wall loaded separately from this factor except for domestic females. "Jumping" loaded on the locomotion factor for wild males but not wild females.

A second factor labeled "grooming" accounted for roughly one-third of the total variance, and loadings on this factor were fairly consistent for all groups. It was noted, however, that "percent time facial grooming" loaded (negative) on this factor for domestic females only.

Except for "defecation" in domestic rats, no other factors could be identified with any degree of certainty. In wild rats, the "defecation" variable was inversely linked with "jumping" for males and with "inactivity 
Table 2

Major Factor Loadings (.60 or Greater) on Open-Field Variables

\begin{tabular}{|c|c|c|c|c|c|c|c|c|c|c|c|c|c|c|c|c|c|c|c|c|}
\hline \multirow[b]{3}{*}{ Factor } & \multicolumn{11}{|c|}{ Wild } & \multicolumn{9}{|c|}{ Domestic } \\
\hline & \multicolumn{6}{|c|}{ Male } & \multicolumn{5}{|c|}{ Female } & \multicolumn{5}{|c|}{ Male } & \multicolumn{4}{|c|}{ Female } \\
\hline & 1 & 2 & 3 & 4 & 5 & 6 & 1 & 2 & 3 & 4 & 5 & 1 & 2 & 3 & 4 & 5 & 1 & 2 & 3 & 4 \\
\hline Proportion Total Variance & .43 & .26 & .10 & .07 & .05 & .04 & .41 & 33 & .12 & .06 & .04 & .50 & .18 & .14 & .09 & .05 & .46 & .31 & .11 & .06 \\
\hline 1. Time on side & -.73 & & & & & & -.96 & & & & & & .74 & & & & & & .79 & \\
\hline 2. Percent ambulation on side & & & & & & .94 & & & -.83 & & & & & & -.97 & & .76 & & .62 & \\
\hline 3. Ambulation on side & .93 & & & & & & .89 & & & & & & & .85 & & & .95 & & & \\
\hline 4. Ambulation in center & .95 & & & & & & .99 & & & & & & & .63 & .64 & & .97 & & & \\
\hline 5. Total ambulation & .96 & & & & & & .98 & & & & & & & .83 & & & .97 & & & \\
\hline 6. Side-center crossings & .92 & & & & & & .96 & & & & & & & .67 & .60 & & .98 & & & \\
\hline 7. Inactivity bouts & & & & & -.66 & & & & .86 & & & & & -.86 & & & -.89 & & & \\
\hline 8. Time inactive & -.73 & & & & & & -.78 & & & & & & & -.91 & & & -.89 & & & \\
\hline 9. Rearing & .94 & & & & & & .98 & & & & & & & & & & .92 & & & \\
\hline 10. Jumping & .69 & & -.60 & & & & & & & .94 & & & & mitted & & & & Omit & ted & \\
\hline 11. Defecation & & & .97 & & & & & & -.71 & & & & & & & .90 & & & & .95 \\
\hline 12. Facial grooming bouts & & .93 & & & & & & .99 & & & & .91 & & & & & & .90 & & \\
\hline 13. Facial grooming time & & .92 & & & & & & .96 & & & & .93 & & & & & & & .81 & \\
\hline 14. Body grooming bouts & & .95 & & & & & & .99 & & & & .94 & & & & & & .96 & & \\
\hline 15. Body grooming time & & & & .90 & & & & .95 & & & & .95 & & & & & & .96 & & \\
\hline 16. Total grooming time & & .88 & & & & & & .97 & & & & .95 & & & & & & .77 & & \\
\hline 17. Percent time facial grooming & & & & & .90 & & & & & & $.9 l$ & & .89 & & & & & -.98 & & \\
\hline
\end{tabular}

bouts" (inverse) and "percent ambulation on the side" (positive relationship) for females. "Percent time facial grooming" loaded differently in all four groups, as did "percent ambulation on the side." It is perhaps significant that a "wall-seeking" factor did not emerge with major loadings on "time on the side" and "percent ambulation on the side."

\section{DISCUSSION}

It appears that the primary effect of domestication on the open-field behavior of Norway rats has been to change the nature and extent of their locomotor behavior. The motor activity of wild rats in the open field was rapid and vigorous relative to that of their domestic counterparts. Such behavior would be adaptive for the wild rat in nature if it were to encounter a totally unfamiliar environment, in that it would facilitate escape or increase its chances of finding shelter, food, etc., and thus facilitate the familiarization process (Barnett, 1958b).

Escape may be a primary motivating factor for the wild rat released in a strange environment. Field studies indicate that rats released in unfamiliar areas seldom become established at these sites and will often travel great distances from the release point (see review by Davis, 1953). While the relatively high ambulation and rearing scores of the wild rats in the present study can be explained in the contexts of both explorationapproach and escape-avoidance, jumping is more clearly an avoidance behavior (Archer, 1973). The fact that jumping by wild rats was significantly greater during Trial 1 than during subsequent trials supports the idea that escape was an initial motivating factor of the wild rats observed in the present study. Huck and Price (1975) also obtained this result and showed that jumping by wild rats was most common at the beginning of each trial, suggesting a degree of habituation to the novel environment both within and between trials. The total lack of jumping by domestic subjects and their more constant levels of activity within and between trials point to the fact that the domestication of the Norway rat has raised its threshold for avoidance behavior in response to a totally unfamuliar environment. This may have been achueved through relaxed selection in captivity and/or artificial selection for docility (low emotionality) associated with the domestication process (Price \& King, 1968).

The rapid and vigorous locomotor behavior of the wild rat in a totally unfamiliar environment stands in sharp contrast to the inhibition of activity displayed when a novel object is placed in an otherwise familiar environment (Cowan \& Barnett, 1975). Generations of selection by traps, poisons, and predators may have rendered the wild rat wary of anything new within their normal sphere of activity. In this context, "freezing" or immobility may be the most adaptive initial response to novelty.

The term "freezing" (in the usual sense) was not used in the present study primarily because of the difficulty in separating this response from the typical resting posture of the rat. Hence, the terms "immobility" or "inactivity" were used instead. The greater inactivity of wild rats, in view of their greater ambulation and grooming scores, presents an interesting paradox. In the open field, the wild rat moves quickly and deliberately, thus amassing high ambulation scores in a short period of time. When it is not ambulating, it is generally either grooming or immobile. The domestic rat in this context ambulates more slowly and spends a great deal of time sniffing and engaged in other body movements of questionable significance. The "stop-and- 
go" behavior of the wild rat in an unfamiliar environment would be adaptive in providing maximum opportunity for stimulus reception ("stop" or attention phase) coupled with rapid and, presumably, adaptive locomotor behavior ("go" phase).

The finding that wild rats spent more time along the arena wall than domestic rats probably denotes a stronger "wall-seeking" tendency among wild rats (Stone, 1932), a response that may facilitate nighttime orientation and avoidance of predators in the natural environment. At the beginning of each trial, when the handling box was raised, wild rats would typically run to the wall of the arena, circle the perimeter a few times, and then exhibit occasional forays into the center sector, particularly during the first $3 \mathrm{~min}$ of testing when activity levels were high. Domestic rats were slower to initiate activity once the startbox was raised and took longer to reach the arena wall. In addition, ambulation in both side and center sectors was distributed more evenly over within-trial periods than was the case for wild rats, who scored nearly as high in both categories during the first 3-min period of each trial as during the remaining four periods combined. A similar trend was noted in between-trial comparisons. Both male and female wild rats traversed proportionately more sectors along the wall in Trial 1 than on subsequent trials. While this same result was true for domestic females, percent ambulation on the side remained relatively constant over trials for domestic males. If orientation to the periphery of the arena is a type of avoidance response in this context, these data again suggest that the wild subjects found the open field more aversive than their domestic counterparts.

In the present study, wild and domestic rats spent $19.1 \%$ and $9.8 \%$ of each $15-\mathrm{min}$ trial, respectively, engaged in grooming activities. Relative to time spent grooming in familiar home cages $(12.5 \%$ of each day for each stock; Price, unpublished data), exposure to the open field increased grooming time by wild rats and decreased grooming time by domestic subjects. If exposure to a new environment is an aversive experience for wild rats, the excessive grooming by wild rats in the open field may represent a form of displacement activity (Armstrong, 1950; Barnett, 1955). This hypothesis is supported by the fact that grooming by wild rats tended to decrease over test days (coinciding with habituation to the open field) while grooming by domestic rats tended to increase with successive exposures to the open field.

Percent time facial grooming was computed in order to examine the hypothesis that grooming by rats in anxiety-producing situations would include a higherthan-normal proportion of facial grooming (Grant, 1963). Hence, it was hypothesized that wild rats would exhibit the greatest increase in the proportion of time facial grooming relative to levels observed in familiar home cages $(27 \%$ and $32 \%$ for wild and domestic rats, respectively; Price, unpublished data). Just the opposite occurred in the present study (Table 1), thus casting some doubt as to the validity of this variable as a measure of displacement grooming.

The open-field test has traditionally been employed in assessing the "emotionality" of rodent species. The difficulties encountered in interpreting open-field activity and defecation in terms of a single emotionality construct have been discussed by Archer (1973) and by Denenberg (1969) in reviews of the open-field literature. The results of the present study emphasize many of these problem dreas. Not only was there a lack of correlation between defecation and the other dependent variables, but wild rats ambulated more than domestic rats despite their higher inactivity scores. The lack of correlation between defecation and the other variables came as no surprise considering the inconsistencies in the literature regarding this variable (see Archer, 1973). On the other hand, wild rats tended to defecate more than domestic rats, a result that was more pronounced in a study (Huck \& Price, 1975) comparing wild and domestic rats reared in enriched and unenriched enclosures. Since this difference can be explained in a number of ways (e.g., stock differences in sympathetic arousal, more vigorous locomotor behavior of wild rats, smaller boluses of wild rats) and since there were not significant changes in defecation rate over trials, this variable appears to be of little use in comparing the response of wild and domestic rats to a novel environment.

Stock and sex differences in the interrelationships of the measures taken in the present study point out the problems encountered in identifying the motivational factors underlying open-field behaviors. Whether the initial responses of wild and domestic rats to a novel environment are guided by different motivational systems (e.g., "fear" vs. "curiosity") or different intensities of a single system (e.g., "fear") can only be answered through appropriate physiological analysis (Cowan \& Barnett, 1975).

The factor analysis proved more useful in supporting older ideas or hypotheses than in generating new ones. Most of the variables loaded on factors labeled "locomotor behavior" and "grooming." Defecation separated out by itself, as did jumping for female wild rats. The finding that the traditional measures of emotionality were not all loaded on a single factor confirms previous reports (Billingslea, 1941, 1942; Holland \& Gupta, 1955; Whimbey \& Denenberg, 1967a, b; Wilcock \& Broadhurst, 1967) and emphasizes the limitations on the use of emotionality as a general construct (Archer, 1973).

The results of the present study generally confirm previously reported differences or similarities in the open-field behavior of wild and domestic Norway rats (Broadhurst, 1958; Farris \& Yeakel, 1945; Huck \& Price, 1975; Hughes, 1975; Price \& Loomis, 1973) and mice (Smith, 1972). One notable exception, however, is the 
discrepancy in the ambulation scores of wild rats (relative to their domestic counterparts) between the present study and the findings reported by Hughes. The use of a square (as opposed to round) arena, which might encourage comel huddling, cannot explain the low ambulation scores of wild rats in Hughes' experiment, since Price and Loomis (1973) also used a square arena and obtained relatively high activity scores for wild rats. The bright lights used for videotaping in Hughes' study could have inhibited the activity of wild rats, as well as the lack of an acclimation period in the open field before release from the startbox.

The wild stock used in the present study were all born to field-trapped females that had conceived in the laboratory. Since many wild-caught females do not breed in captivity. the representativeness of the wild stock used in the present study was in doubt. Hence, 10 wild males, born in the laboratory to 6 females that had conceived in nature, were tested and compared to the 10 laboratory-conceived wild males used in the present study. No statistically significant differences were found in the scores of the two groups.

\section{REFERENCES}

Archer, J. Tests for emotionality in rats and mice: A review. Animal Behavour, 1973, 21, 205-235.

Armstrong, E. A. The nature and functions of displacement activities. Symposia of the Society of Expenmental Biology, $1950,4,361-384$.

Barnett, S. A. "Displacement" behavior and "psychosomatic" disorder. Lancet, 1955, 269, 1203-1208.

Barnett, S. A. Expenments on "neophobia" in wild and laboratory rats. British Journal of Psychology, 1958a, 49. $195-201$.

Barnett. S. A. Exploratory behavior. Bntish Journal of Psychology, 1958 b $, 49,289-310$.

Bllingslea, $F, Y$ The relationship between emotionality and vamous other saluents of behavior in the rat. Journal of Comparative Psychology, 1941,31,69-77.

Bullngslea, $F$. Y. Intercorrelational analysis of certain behavior salients in the rat. Journal of Comparative Psychology. $1942,34,203-211$.

Boice, R. Domestication. Psychological Bulletin, 1973, 80. 215-230.

Broadhurst. P. L. Determinants of emotionality in the rat III Strain differences. Journal of Comparative and Physiological Psychology, 1958,51,55-59.
Chitty, D. The study of the brown rat and its control by poison. In D. Chitty (Ed.), Control of rats and mice Vol. I. Oxford: Clarendon Press, 1954. Pp. 160-305.

Cowan, P. E.. \& Barnett, S. A. The new-object and new-place reactions of Rattus rattus L. Zoological Journal of the Linnean Society, $1975,56,219-234$

Dans, D. E. The characteristics of rat populations. Quarterly Renew of Biology, 1953, 28, 373-401.

Denenberg, V. H. Open-field behavior in the rat: What does it mean? Annals of the New York Academy of Science, 1969 , $159,852-859$.

Farns, E. J., \& Yeakel, E. H. Emotional behavior of gray Norway and Wistar albino rats. Journal of Comparative Psychology. $1945,38,109-118$.

Grant, E. C. An analysis of the social behavior of the male laboratory rat. Behaviour, 1963, 21, 260-281.

Holland, H. C.. \& Gupta, B. D. Some correlated measures of activity and reactivity in two strains of rats selectively bred for differences in the acquisition of a conditioned avordance response. Animal Behaviour, 1966, 14, 574-580.

Huck, U. W., \& Price, E. O. Differential eifects of environmentai ennchment on the open-field behavior of wild and domestic Norway rats. Journal of Comparative and Physiological Psychology, 1975.89,892-898.

Hughes, C. W. Early experience in domestication. Journal of Comparative and Physiological Psychology, 1975, 88. 407-417.

Price. E. O., \& King, J. A. Domestication and adaptation. In E. S E Hafez (Ed.), Adaptation of domestic animals Phuadelphia. Lea \& Febiger, 1968 , Pp. 35-45.

Price, E. O., \& Loomis, $S$ Maternal influence on the response of wild and dornestic Norway rats to a novel environment. Development Psychoblology, 1973,6,203-208.

Shorten, $M$. The reaction of the brown rat toward changes in its environment. In $D$. Chitty (Ed.), Control of rats and its envice. Vol. II. Oxford: Clarendon Press. 1954. Pp. 307-334.

Sloan. R. J. Relationships between behavior and reproduction in captive wild $\Lambda$ orway rats (Rattus norvegicus). Unpublished doctoral dissertation, SUNY College of Environmental Sc1ence and Forestry, 1973.

Smith, R. H. Wildness and domestication in Yus musculus: A behavioral analysis. Journal of Comparative and Physiological Psychology, 1972,79, 22-29.

Sokal, R R., \& Rohlf, F J. Biometry, San Frannisco: Freeman, 1969 .

Stone, C. P. Wildness and savageness in rats of different strains. In K. S. Lashley (Ed.). Studies in the dynamics of behavior. Chicago: University of Chicago Press, 1932. Pp. 14-55.

Whimbey, A. E., \& Denenberg, V. H. Two independent behavioral dimensions in open-field performance. Journal of Comparative and Physiological Psychology, 1967a, 63, 500-504.

Whimbey, A. E., \& Denenberg, V. H. Experimental programming of life histories: the factor structure underlying experimentally created individual differences. Behaviour, $1967 \mathrm{~b}, 29$, 296-314.

Wilcock, J., \& Broadhurst, P. J. Strain differences in emotionality: open-field and conditioned avoidance behavior in the rat. Journal of Comparative and Physiological Psychology, $1967,63,335-338$.

(Recelved for publication October 24, 1974; revision accepted September 15,1975 .) 